This is the Author Accepted Version of the paper

Yap, Y., M. Gibson, H., and J. Waterson, B. (2015).

"Models of Roundabout Lane Capacity."

J. Transp. Eng., 141(7), doi: 10.1061/(ASCE)TE.1943-5436.0000773

\title{
Models of Roundabout Lane Capacity
}

\section{Yok Hoe Yap}

Postgraduate Researcher

Transportation Research Group,

Engineering and the Environment,

University of Southampton,

Southampton SO16 7QF,

United Kingdom

\section{Dr. Helen M. Gibson}

Visiting Research Fellow

Transportation Research Group,

Engineering and the Environment, University of Southampton,

Southampton SO16 7QF,

United Kingdom

\section{Dr. Ben J. Waterson}

Lecturer

Transportation Research Group,

Engineering and the Environment,

University of Southampton,

Southampton SO16 7QF,

United Kingdom

Subject headings: Intersections, Traffic capacity, Traffic models, Empirical equations, Neural networks.

Abstract

Accurate roundabout capacity models are essential for optimal roundabout designs, but there exists significant differences in the predicted capacities of various state-of-the-art models and in their included explanatory variables. An empirical study into roundabout lane entry capacity was thus performed in the U.K. using data from 35 roundabout entry lanes, where various model forms and explanatory variable sets were tested. Two regression models and an artificial neural network were developed. A negative exponential relationship with circulating flow predicted lane capacity better at high and low circulating flows, and better reflected the overall trends in the aggregated capacity data compared to a linear model. The regression models performed relatively well, and provided better information on the impacts of the variables than the neural network. The models consistently suggest that entryexit separation and flows exiting on the same arm have stronger significant effects 
on capacity than variables such as entry angle and entry radius. These findings could thus contribute to an improved understanding of the variables which affect entry lane capacity and therefore the development of better roundabout capacity models.

\section{Introduction}

Roundabouts are a major form of at-grade junction, and operate based on offside priority where entering vehicles give way to those circulating one-way around a central island. Their traffic performance in terms of queues and delays typically depends on entry capacity, which is the maximum sustainable throughput of vehicles across the give-way line of an entry with fully-saturated demand. Offside priority means that this primarily depends on the circulating flow, but many other traffic, geometric and environmental factors have also been found to affect entry capacity. Existing capacity models for roundabouts are based on at least one or more of three major methodologies: empirical approaches based on statistical evidence from observed roundabout capacity measurements, gap acceptance based on theoretical models of driver behavior and vehicle interactions, and microscopic simulation of the movements and interactions of individual vehicles on a simulated network (Yap et al. 2013).

In the design of roundabouts, the geometric layout is the most crucial aspect for achieving the required operational performance as the designer has little control over traffic and environmental variables. Hence, understanding the impact of changes in geometry on capacity is vital. Of the major empirical models, the linearin-Q $Q_{c}$ LR942 model (Kimber 1980) of ARCADY (TRL Software 2012) is sensitive to the most geometric variables, given its basis in data from track experiments and a very large sample of public roundabouts of various geometries to determine the entry capacity of whole approaches. Other empirical models such as the French Girabase (Guichet 1997) and U.S. HCM 2010 (Transportation Research Board 2010) relied more on theoretical models; for example, their negative exponential relationship between $Q_{e}$ and $Q_{c}$ parallels that of the Siegloch gap acceptance model (Akçelik 2011; Louah 1992). In comparison, other models such as SIDRA (Akcelik \& Associates Pty Ltd 2011) and the Swiss Bovy-Tan (Simon 1991) model, being more heavily based on gap acceptance theory and/or microscopic simulation, took more account of traffic variables and driver behavior.

However, as discussed in Yap et al. (2013), despite the relative similarity of how roundabouts operate worldwide, there can be large differences in prediction between the major capacity models. Given that the models significantly rely on empirical data from their origin countries, part of these errors may be attributed to differences in driver and vehicle behavior in different populations. However, the differences in explanatory variables used and the size of the model predictive errors also suggest that the models may not have adequately accounted for all the factors and processes affecting roundabout capacity, at least to a level which enables transferability without relatively arbitrary calibration measures.

The research in this paper thus attempts to develop a better understanding of whether existing models are adequate given possible differences in geographical context, roundabout design, driver and/or vehicle behavior, and whether further model development is needed to adequately describe the effects of factors and variables on roundabout capacity for improved predictive ability and model transferability. 
In line with the objectives, it was necessary to collect up-to-date capacity and input data from the field for the assessment of existing models, and to investigate the relationships between at-capacity entry flows and geometric or traffic variables. Determining these relationships was particularly important given the disparities in the forms of capacity models and significant variables in existing literature. An empirical methodology with directly-measured capacity flow data was used, in preference to a gap acceptance approach involving intermediary driving or traffic behavior models based on headway measurements which could introduce additional uncertainty into the relationships between geometry and capacity.

Sample selection for an empirical investigation should ideally maximize the range of each variable to be investigated, with random and/or stratified sampling to improve the sample's representativeness. However, the need for direct measurement of at-capacity entry flows meant that the sites were limited to those which had sustained queues at the give-way line during peak periods - the queues indicated an excess of demand over capacity (i.e. the maximum flow for the given conditions) and the resulting entry flows therefore reflected the capacity. Desktopbased reconnaissance using live traffic information (Google 2012; Hampshire County Council 2005) and local knowledge was used to identify congested roundabout entries. Geometric measurements were based on high-resolution aerial or satellite photographs (Google Inc. 2013) scaled to superimposed Ordnance Survey digital mapping (Ordnance Survey 2012) in CAD software (Autodesk Inc. 2012). The final sample comprised of data from 35 lanes in 19 entries to 10 roundabouts in Hampshire and Berkshire (Table 1), representing a wide range of geometry and roundabout sizes (Table 2).

The at-capacity entry flow $\left(Q_{e}\right)$ and the corresponding circulating flow $\left(Q_{c}\right)$ and exiting flow $\left(Q_{x}\right.$ leaving on the same arm as the subject entry) were enumerated from digital videos recorded from the roundabout entries during peak periods. This involved recording the number of vehicles crossing the respective positions illustrated in Figure 1, during one-minute periods with continuous queuing at the entry yield line and uninterrupted circulating flows The passenger car unit (pcu) factor for heavy vehicles was taken to be 2 pcu based on existing studies (Kimber 1980; Rodegerdts et al. 2007, table 44), given the relative insensitivity of $Q_{\mathrm{e}}$ to the rounding of pcu values (Glen et al. 1978; Semmens 1988). 1753 one-minute flow data points were obtained, although 193 did not include exiting flows due to recording limitations.

The explanatory variables (listed in Table 2 and shown in Figure 1) were selected on the basis of previous roundabout studies (Guichet 1997; Kimber 1980; Tan 1991; Troutbeck 1989), and included several two-way interactions between them where appropriate. As this study focused on lane capacity rather than wholeapproach capacity, lane width was used in lieu of flare geometry variables, particularly as several sites also had approach half-width $\mathrm{V}$ greater than lane entry width $\mathrm{E}$. The lane width $10 \mathrm{~m}$ upstream of the give-way line $\left(\mathrm{W}_{\mathrm{L}}\right)$ was generally found during the subsequent analyses to produce better model fit compared to $E$, as the latter was sensitive to the final flare geometry at the entry and could thus be less representative of the conditions at entry during the gap acceptance process.

It was generally observed that entering vehicles gave way to all circulating vehicles regardless of entry lane position (although this may not be the case for other roundabout entries where the first downstream exits are much further and inner circulating vehicles do not change lanes until they exit). Hence, only the upstream 
112 circulation width $\left(\mathrm{W}_{\mathrm{C}}\right)$ was investigated due to its possible influence on circulating

113 vehicle headways (Troutbeck 1989). Similarly, as queued delay could affect critical

114 gaps and thus capacity (Ashworth and Bottom 1977; Polus et al. 2003; Polus et al.

115 2005), the duration of the queues (as a proxy to average queued delays) was also investigated, as was the adverse effects of wet weather (Tenekeci et al. 2010).

Additional short lanes in flared entries can affect measured lane entry flows, since a vehicle which changes lanes leaves behind a gap in the queue which may not be closed by the next vehicle before it reaches the give-way line. This could be significant if the queue has a fast move-up rate with many lane changes, and prevents measurement of the entry capacity of the lanes at the give-way line as restricted by offside priority (as opposed to that restricted by the supply from upstream approach or link). Hence, data points were measured from periods which uninterrupted continuous queues were present, defined by the presence of at least one vehicle at or near the give-way line at all times. This was to some extent subjective, as it was based on observation of the acceleration/deceleration of vehicles and their relative positions and headways. Investigation of the effects of flaring on lane capacity will necessarily require more data from more entries of different flare lengths and lane choice patterns, but this was beyond the scope of this study.

\section{Evaluation of existing models \\ Observed data}

The first step of the process to assess the existing models and identify possible relationships between the inputs and capacity comprised exploratory data analyses of the data obtained from the survey. At-capacity entry flows are plotted against the corresponding circulating flows in Figure 2 along with local regression (loess) lines, which are least-squares polynomial lines fitted to localized subsets of the data and weighted using nearest-neighbors algorithms (Cleveland 1994, chapter 3.7). There appears to be a clear non-linear trend in the aggregated data; however, the typically limited range of observed circulating flows (which depended on the prevailing origin-destination patterns at the roundabout during the peak hour periods) meant that a non-linear relationship is less evident within individual sites.

A few sites had significantly steeper slopes compared to others with a similar circulating range, while there were also differences in entry flow 'intercept' among those with similar slopes. Within individual sites, there was little evidence of heteroscedasticity across the circulating flow range, although this may have been due to the limited number of data points at low and/or high circulating flows as seen in the example in Figure 3.

\section{Existing model predictions}

To evaluate their predictive ability for a new set of roundabouts, the predicted and actual entry flows were compared for several existing major capacity models in their default form, albeit with appropriate assumptions to estimate lane capacity where necessary e.g. by treating each lane as a single-lane approach. The models tested were the LR942 model of ARCADY, the HCM 2010 model, the German Brilon-Wu model (Wu 2001), the Swiss Bovy-Tan model and the SIDRA model.

The results are shown in Figure 4. Some of the predictive errors could possibly be attributed to differences in behavior between different driver or vehicle populations (for example, the HCM2010 model was calibrated to data from U.S. drivers who may generally have had less experience with roundabouts compared to say, U.K. drivers). Nevertheless, the U.K.-based LR942 model - which was extensively validated in the 1990's (Barnard et al., unpublished report, 1995) - did 
not show much better performance for predicting lane capacity, although this could partly be due to its focus on whole-approach capacity particularly for multilane flared entries. However, most of the models show a systematic trend of greater underprediction of lane capacity at higher entry flows (corresponding to lower circulating flows), suggesting that there could be other reasons for their limited accuracies when applied to this new dataset.

These capacity prediction errors could be reduced by using relevant sitespecific measurements such as critical gaps or recommended calibration methods such as intercept corrections or 'environment factors'. However, such procedures would not reflect how these models could be applied to new roundabouts in the absence of local information, and it is not clear how further changes in geometry affect parameters which have been calibrated (Yap et al. 2013). Thus, the results here point to the need for improved models to more accurately predict lane entry capacity, and to have a better understanding of factors affecting capacity given the differences in inputs of existing models.

\section{Development of improved models}

\section{Regression approach}

Using the available data, new empirical models were developed using statistical methods such as multiple linear or nonlinear regression; further information on these methods can be found in many statistical textbooks such as Kutner et al. (2005) and Cohen et al. (2003). Previous empirical studies (Brilon and Stuwe 1993; Glen et al. 1978; Kimber 1980; Kimber and Semmens 1977; Louah 1992; Polus and Shmueli 1997; Rodegerdts et al. 2007; Semmens 1988) variously used linear or negative exponential relationships between $Q_{e}$ and $Q_{c}$. To investigate the best regression form for the analyses here, smaller 30-second measurement time intervals were used in several roundabouts, with observations in both morning and afternoon peak periods to widen the range of circulating flows (data points from different periods did not show any statistically-significant differences in linear slopes and intercepts, and so were combined together; likewise, there were no statistical differences between 30-second and one-minute regression lines). As shown by the example in Figure 3, these did not conclusively show that nonlinear relationships were better than linear for individual roundabouts, despite the wider range of circulating flows. However, the slopes of the linear model for large and gradeseparated roundabouts had previously been found to depend on prevailing circulating flows (Semmens 1988), while Figure 2 suggests that a nonlinear relationship could be more appropriate in the absence of advance knowledge of the applicable circulating flow range for a proposed roundabout.

Both linear-in- $Q_{c}$ and exponential-in- $Q_{c}$ forms were therefore investigated in the regression analyses, using one-minute data points for all sites. The 'slopes' and/or 'intercepts' appeared to be site-specific, so the tested models were linear with input-dependent intercept and gradient $\left(Q_{e}=A+B Q_{c}\right)$, or negative exponential with constant or input-dependent asymptote, 'slope' and/or 'intercept' $\left(Q_{e}=A e^{B Q_{c}}+C\right)$; $A, B$ and/or $C$ was $m+\Sigma p_{i} X_{i}$ where $X_{i}$ were included explanatory variables, $m$ and $p_{i}$ were parameters to be determined through least-squares regression. Quadratic or piecewise linear spline functions in $Q_{c}$ were also investigated but they suggested counterintuitive behavior within the range of observed data, such as increasing capacity at very high circulating flows.

Based on the residual scatterplots and previous studies (Marstrand 1988; Troutbeck 1989), a nonlinear relationship between $Q_{e}$ and $D$ was tested using $D^{2}$ or two-way $D$ interaction terms. There was little consistent evidence to suggest the form 
212 of the relationship between $Q_{e}$ and the other explanatory variables so simple linear 213 additive effects were assumed, complemented by checks on the regression 214 assumptions through residual scatterplots.

The regression models assumed additive, homoscedastic and normallydistributed errors $(\varepsilon)$, as part of the observed entry flow variability is likely to be from driver and vehicle characteristics which were not explicitly included in the model; there was no evidence from the scatterplots to show that these were proportionate to $\mathrm{Q}_{\mathrm{e}}$ nor that the assumptions were inappropriate. For the nonlinear exponential model, least-squares error minimization using numerical methods was used to estimate the parameters; statistical inferences assumed large-sample theory as the similarity of confidence intervals from bootstrap sampling and asymptotic nonlinear regression did not suggest this to be inappropriate (as explained in Kutner et al. 2005, p.529).

Backwards elimination with all (and various subsets of) the variables in Table 2 showed that many variable coefficients were significant at the $5 \%$ level due to the large sample size, despite having relatively little contribution to explained variability. There was also limited information within existing studies regarding the relative importance of the explanatory variables, apart from circulating flow and diameter. Hence, hierarchical forward variable selection was used to develop more parsimonious final models, with the main effect and interaction terms entered manually based on the improvements in adjusted $R^{2}$ observed during the stepwise regression process.

All the regression (and the neural networks discussed in the following section) analyses were performed in SPSS (IBM Corporation 2012a). Over 210 regression models were investigated, and although these were not exhaustive given the number of possible combinations of variables and their interactions, the final models below (and Table 3) represent the best combinations based on the process outlined earlier:

Model 1: Multiple linear regression $\left(R^{2}=0.825\right.$, adjusted $R^{2}=0.824$, root-meansquare-error RMSE $=126.5$ ):

$\mathrm{Q}_{\mathrm{e}}=1113+15.9 \mathrm{D}-5.99 \mathrm{~d}_{\text {sep }}-0.243 \mathrm{D} \cdot \mathrm{d}_{\text {sep }}+0.0103 \mathrm{Q}_{\mathrm{x}}-7801(1 / \mathrm{r})+0.00435 \mathrm{Q}_{\mathrm{x}} \cdot \mathrm{d}_{\text {sep }}$ $+\left[-0.952-0.00313 \mathrm{D}+0.0153 \mathrm{~d}_{\mathrm{sep}}-0.000108 \mathrm{Q}_{\mathrm{x}}+7.51(1 / \mathrm{r})\right] \mathrm{Q}_{\mathrm{c}}$

Model 2: Nonlinear exponential regression model with additive error and variable asymptote $\left(R^{2}=0.839\right.$, adj. $\left.R^{2}=0.838, R M S E=121.3\right)$ :

$\mathrm{Q}_{\mathrm{e}}=-771+8.01 \mathrm{D}+7.00 \mathrm{~d}_{\text {sep }}-0.103 \mathrm{D} \cdot \mathrm{d}_{\text {sep }}+0.0572 \mathrm{Q}_{\mathrm{x}}+2088(1 / \mathrm{r})+40.7 \mathrm{~W}_{\mathrm{C}}$ +1580 EXP( $\left.-0.00103 \mathrm{Q}_{\mathrm{c}}\right)$

Despite having only five and six traffic and geometric variables respectively, the linear and exponential models above compared favorably to models of equivalent form but including all other variables and interaction terms (those had adjusted $R^{2}$ values of 0.835 and 0.842 ). For the exponential model, an alternative model form which had the exiting flow $Q_{x}$ as part of a conflicting flow (i.e. $Q_{c}+k \cdot Q_{x}$ or $Q_{c}+k \cdot d_{s e p} \cdot Q_{x}$ in place of $Q_{c}$ ) did not show an improvement in model fit. Other additive-error exponential models using input-dependent 'slopes' and 'intercepts' did not improve on the model fit, while the implied complex interactions among the variables in these models were difficult to justify. Exponential models with multiplicative error terms and

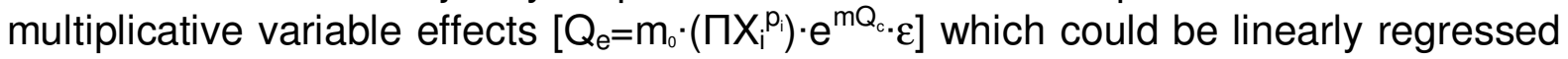
via logarithmic transformation also produced poorer fits to the data. Model forms based on the LR942, Girabase, Brilon-Wu and SR45 (Troutbeck 1989) capacity models were also tested by recalibrating their parameters for the new dataset, but these also produced poorer model fit. 


\section{Neural network modelling}

An important alternative to statistical regression models for data analysis and pattern recognition in large datasets is the artificial neural network (NN). This is a mathematical model represented by a layer of input nodes, a layer of output nodes (where the numbers of nodes in each layer depend on the number or type of input and output variables respectively), and typically at least one layer of hidden units with sigmoidal activation functions which transform the combined weighted inputs from preceding layers into an output value. The connections between the nodes in successive layers depend on weights and biases whose values are optimized through learning algorithms from a set of training data. Appropriately-structured and trained NN's can approximate complex nonlinear relationships with interactions between input variables (see Kutner et al. 2005 chapter 13.6 and Sarle 1994 for further information), and has been used in various transportation studies (Karlaftis and Vlahogianni 2011; Özuysal et al. 2009). Given the uncertainties around the form of the capacity relationships shown by the differences in existing models and in the exploratory scatterplots, NN modelling was thus used in this study to assess the ability of the regression models above to represent the relationships between the input and capacity, given the constraints of assumed functional relationships. It also enabled the determination of the extent to which the observed variation in the capacity could be explained by the inclusion of the selected explanatory variables, in the absence of any a priori relationship forms and interactions.

The dataset of explanatory variables and capacity flows was used to develop and train a simple feed-forward multilayer perceptron with a single hidden layer using hyperbolic tangent activation functions. The number of hidden nodes was determined through progressive removal or inclusion of hidden units based on the changes in training errors, while weights and biases were optimized through error back-propagation using numerical methods to minimize the sum-of-squares error. To account for the stochastic nature of the NN optimization process (IBM Corporation $2012 b, p .5)$, ten NN's were developed for each set of explanatory variables. It was found that NN's with all the variables included had an average $R^{2}$ of 0.877 . However, as shown in Table 4, NN's with a subset of 4 or 5 variables including either exiting flow or entry-exit separation was sufficient to account for most of the model fit.

\section{Discussion}

As shown in Figures 5, 6 and 7, the inherent flexibility of the neural network models enabled them to produce the best fits to the observed data, but given that scatterplots of predicted capacity from the all-variable NN's appeared to indicate some over-fitting, the linear and exponential regression models would be preferred for engineering application due to their comparable predictive ability and easier interpretation of variable effects. Although the exponential Model 2 provided marginally better overall fit, linear Model 1 was a slightly better fit for sites with steeper slopes despite slightly under-predicting at low and high circulating flows (Figures 5 and 6). Hence, although the nonlinear relationship between entry capacity and circulating flow across the whole dataset could be represented by either an exponential-in- $Q_{c}$ model or a linear-in- $Q_{c}$ model with interactions, the latter may be less accurate at very low or very high circulating flows.

Figure 7 shows that the RMSE of the existing capacity models in default form exceeded those of the new empirical models, by a minimum of $60 \mathrm{pcu} / \mathrm{h}$ or $50 \%$ when compared against the regression models. While the performance of the existing models could be acceptable in their origin countries, ongoing research and development (e.g. Brilon 2014, Rodegerdts 2014) suggests that there is scope for 
310 improvement, not least to better account for site-to-site variation. And although the 311 lower errors are not unexpected given that the new models have been specifically calibrated to this particular dataset, the size of the errors further illustrates the limited accuracy of existing models when applied to new roundabouts without calibration, and also the potential improvement in accuracy possible with the inclusion of additional explanatory variables in an appropriate form.

The regression and neural network analyses show that the circulating flow and diameter were the most important explanatory variables for lane entry capacity. At the other end, queue duration and wet weather had insignificant impacts, although the latter may have been due to the lack of data from heavy rain conditions. Between these, separation and exiting flow appear to contribute significantly more to the fit of the models compared to other variables such as entry radius, entry angle and lane width (Table 5).

Assuming all other variables were unchanged with realistic values for interacting explanatory variables, the effect of larger diameter was to increase the lane entry capacity in both regression models, although this increase was less at higher circulating flows in Model 1. Greater circulating width significantly increased capacity in Model 2 but not in Model 1, illustrating the sensitivity of the parameter effects to the form of the assumed relationships. In contrast to SIDRA and LR942, both models suggested that greater entry curvature increased capacity (except at lower $Q_{c}$ in Model 1), although the effects of both entry curvature and circulating width were quite weak compared to other variables. Variables thought to have greater impact such as entry angle and entry width (Akcelik \& Associates Pty Ltd 2011; Kimber 1980) also appeared to have comparatively weak or insignificant effects, although it is likely that entry width would be more important for the overall capacity of flared entries compared to a single line of queuing vehicles.

The regression and neural network analyses consistently suggest that separation and exiting flow had significant and relatively important effects on lane entry capacity, beyond those of inscribed circle diameter. Although a few previous studies found that exiting flows or separation do not usually or significantly affect entry capacity (Kimber 1980; Kimber and Semmens 1977; Troutbeck 1990), others found a separation-dependent negative impact of exiting flow (Hagring 2001; Louah 1992; Mereszczak et al. 2006; Tan 1991), while Semmens (1988) found that larger separation reduced the $Q_{e}$ intercept for very large roundabouts greater than $130 \mathrm{~m}$ in diameter. The Girabase model (Guichet 1997) in contrast predicts an increase in capacity with larger exiting flows, apart from large roundabouts with small separation. However, both the linear and exponential regression models above suggest a more complex relationship than those previously seen, where for example, larger exiting flows appear to increase capacity at low circulating flows regardless of roundabout size or separation (Figure 8); this suggests a need for further research into the effects of exiting flows and separation on lane capacity.

Resource limitations and thus the limited sample size available for model calibration and validation mean that there are a number of caveats to the findings above. For example, queues and delays are more important measures of performance for intersections, but could not be included within the scope of this study as they are modelled separately and field measurements were not available. Although the chosen sample attempted to maximize the range of each of the variables, it was ultimately limited by the availability of entry lanes with measurable capacity flows, which in turn could also limit the generalizability of the findings to all roundabouts especially with other driver and vehicle populations. The statistical 
significance of regression parameters may have been affected by collinearity 361 between several of the variables arising from the constraints on the geometric layout imposed by design guidelines, vehicle swept paths and geometric compatibility. Although a large number of different regression model forms were investigated, there remains a possibility that another model form could more accurately describe the effects of the variables on capacity, although the neural network modelling suggested that this improvement would likely be limited. Furthermore, the "noise" in the flow measurements from the short time intervals did not allow the determination through exploratory data analyses of more definitive functional forms of the relationship between many variables and $Q_{e}$, while there was also limited theoretical background available for this purpose - further research to address this could then explain the discrepancies between the two regression models in terms of the impacts of the variables on capacity. Also, the empirical models here have focused on lane capacities by excluding the effects of flaring which could significantly reduce the usable capacity; in flared roundabout entries, additional modelling such as the Entry Lane Simulation of ARCADY / Junctions 8 (TRL Software 2012) will be required to account for the reduction in lane entry flows caused by entry starvation due to lane choice patterns and lane queues.

In light of several of these caveats, the new models were tested by retaining a proportion of the dataset (comprising data from a given site) for validation rather than for calibration. The results for two sites are shown in Figure 9; notwithstanding the reduced dataset used to calibrate their parameters, the regression models provided a reasonably good fit to the actual observed capacities. In contrast, the NN had poor transferability due to over-fitting, and therefore was likely to be less appropriate for predictive purposes. However, for the final regression models to be more suitable for wider use, further validation with other datasets would be needed to assess their transferability to other sites without recalibration; otherwise, a practical calibration facility would have to be developed given that driving behavior (which may not be wholly determined by roundabout geometry) or other unquantifiable factors could have significant impacts on capacity.

\section{Conclusions}

An exploratory empirical study on lane entry capacity has been performed using at-capacity flow and geometric data from 35 roundabout entry lanes in Hampshire and Berkshire. There is limited evidence of non-linear relationships between lane entry capacity and circulating flows for individual sites, due primarily to the limited range of observable circulating flows. However, the aggregated data on a wider scale shows a distinct non-linear relationship between entry flow and circulating flow.

Existing capacity models showed relatively limited predictive accuracy for this dataset, with many under-predicting lane entry flows particularly at lower circulating flows. Hence, a linear-in- $Q_{c}$ model and a nonlinear exponential-in- $Q_{c}$ model were developed through least-squares regression, where the former accounted for over $82 \%$ of the variability in the data and the latter showed similar performance. The linear model provided better fit for several sites, but the nonlinear model had better accuracy at the high and low ends of the circulating flow range. The performances of both regression models were close to the more flexible neural network models which were developed as benchmarks for predictive performance.

It was found that the inclusion of only a few explanatory variables was sufficient to explain most of the variability. Among these, the entry-exit separation distance and exiting flows were found to produce significant contributions to the 
model fits, more than variables such as entry width and entry angle. However, their interactions with other variables imply a more complex relationship than those which have been found by previous studies.

\section{Acknowledgements}

The authors thank Dr. Xiaoyan Zhang and Graham Burtenshaw of TRL Limited as well as the anonymous reviewers for their comments, and the Government of Brunei Darussalam for sponsoring the first author's doctoral research. References

Akcelik \& Associates Pty Ltd. (2011). "SIDRA Intersection version 5.1", Akcelik \& Associates Pty Ltd, Greythorn, Victoria.

Akçelik, R. (2011). "An assessment of the Highway Capacity Manual 2010 roundabout capacity model". 3rd International Conference on Roundabouts, 18-20 May 2011, Carmel, Indiana, U.S.A.

Ashworth, R., and Bottom, C. G. (1977). "Some observations of driver gapacceptance behaviour at a priority intersection." Traffic Engineering and Control, 18(12), 569-517.

Autodesk Inc. (2012). "AutoCAD Civil 3D 2013" (software), Autodesk Inc., San Rafael, CA

Brilon, W., and Stuwe, B. (1993). "Capacity and Design of Traffic Circles in Germany." Transportation Research Record, 1398, 61-67.

Brilon, W. (2014). "Roundabouts: a State of the Art in Germany." 4th International Conference on Roundabouts, Transportation Research Board, Seattle, Washington.

Cleveland, W. S. (1994). The Elements of Graphing Data, Hobart Press, New Jersey. Cohen, J., Cohen, P., West, S. G., and Aiken, L. S. (2003). Applied Multiple Regression/Correlation Analysis for the Behavioral Sciences, Lawrence Erlbaum Associates, New Jersey.

Glen, M. G. M., Sumner, S. L., and Kimber, R. M. (1978). "SR436 The capacity of offside priority roundabout entries." Transport and Road Research Laboratory, Crowthorne.

Google (2012). "Google Maps." <http://maps.google.co.uk>. (May-August, 2012).

Google Inc. (2013). "Google Earth", version 7.1 (software), San Rafael, CA.

Guichet, B. (1997). "Roundabouts in France: Development, Safety, Design, and Capacity." Proc., Third International Symposium on Intersections without Traffic Signals, University of Idaho, 100-105.

Hagring, O. (2001). "Derivation of Capacity Equation for Roundabout Entry with Mixed Circulating and Exiting Flows." Transportation Research Record, 1776, 9199.

Hampshire County Council (2005). "ROMANSE." <http://www.romanse.org.uk>. (April-July, 2012).

IBM Corporation (2012a). "IBM SPSS Neural Networks 21." IBM Corporation, Armonk, New York.

IBM Corporation (2012b). "IBM SPSS Statistics", version 21 (software), IBM Corporation, Armonk, New York.

Karlaftis, M. G., and Vlahogianni, E. I. (2011). "Statistical methods versus neural networks in transportation research: Differences, similarities and some insights." Transportation Research Part C: Emerging Technologies, 19(3), 387-399.

Kimber, R. M. (1980). "LR942 The traffic capacity of roundabouts." Transport and Road Research Laboratory, Crowthorne. 
Kimber, R. M., and Semmens, M. C. (1977). "SR334 A track experiment on the entry capacities of offside priority roundabouts." Transport and Road Research Laboratory, Crowthorne.

Kutner, M. H., Neter, J., Nachtsheim, C. J., and Li, W. (2005). Applied Linear Statistical Models, McGraw-Hill, New York.

Louah, G. (1992). "Panorama critique des modeles français de capacité des carrefours giratoires." Proc., Actes du séminaire international "Giratoires 92", Centre d'Etudes des Transports Urbains, 213-228.

Marstrand, E. B. (1988). "The Capacity of Large Roundabouts." Highways and Transportation, 35, 9-12.

Mereszczak, Y., Dixon, M., Kyte, M., Rodegerdts, L., and Blogg, M. (2006). "Including Exiting Vehicles in Capacity Estimation at Single-Lane U.S. Roundabouts." Transportation Research Record, 1988, 23-30.

Ordnance Survey (2012). "OS MasterMap Topography Layer." $<$ http://digimap.edina.ac.uk>. (May-July, 2012).

Özuysal, M., Çalışkanelli, S. P., Tanyel, S., and Baran, T. (2009). "Capacity prediction for traffic circles: applicability of ANN." Transport, 162(TR4), 195-206.

Polus, A., Lazar, S. S., and Livneh, M. (2003). "Critical Gap as a Function of Waiting Time in Determining Roundabout Capacity." Journal of Transportation Engineering, 129(5), 504-509.

Polus, A., Shiftan, Y., and Shmueli-Lazar, S. (2005). "Evaluation of the Waiting-Time effect on Critical Gaps at Roundabouts by a Logit Model." European Journal of Transport and Infrastructure Research, 5(1), 1-12.

Polus, A., and Shmueli, S. (1997). "Analysis and evaluation of the capacity of roundabouts." Transportation Research Record, 1572, 99-104.

Rodegerdts, L. (2014). "Reassessment of Roundabout Capacity Models for the Highway Capacity Manual." 4th International Roundabout Conference, Transportation Research Board, Seattle, Washington.

Rodegerdts, L., Blogg, M., Wemple, E., Myers, E., Kyte, M., Dixon, M., List, G., Flannery, A., Troutbeck, R., Brilon, W., Wu, N., Persaud, B., Lyon, C., Harkey, D., and Carter, D. (2007). "National Cooperative Highway Research Program (NCHRP) Report 572: Roundabouts in the United States." Transportation Research Board of the National Academies, Washington, D.C.

Sarle, W. S. (1994). "Neural Networks and Statistical Models." Proc., Nineteenth Annual SAS Users Group International Conference, SAS Institute Inc., 1538-1550.

Semmens, M. C. (1988). "RR142 The capacity of entries to very large roundabouts." TRRL Research Report, Transport and Road Research Laboratory, Crowthorne.

Simon, M. J. (1991). "Roundabouts in Switzerland: Recent Experiences, Capacity, Swiss Roundabout Guide." Proc., Intersections without Traffic Signals II: Proceedings of an International Workshop, Springer-Verlag, 41-52.

Tan, J.-a. (1991). "A Microscopic Simulation Model of Roundabout Entry Operations." Proc., Intersections without Traffic Signals II: Proceedings of an International Workshop, Springer-Verlag, 159-176.

Tenekeci, G., Montgomery, F., and Wainaina, S. (2010). "Roundabout capacity in adverse weather and light conditions." Transport, 163(TR1), 29-39.

Transportation Research Board (2010). Highway Capacity Manual 2010, Transportation Research Board, Washington D.C.

TRL Software. (2012). "Junctions 8", version 8.0.1.305 (software), TRL Software, Wokingham. 
508 Troutbeck, R. J. (1989). "SR45 Evaluating the Performance of a Roundabout." 509 Australian Road Research Board, Vermont South, Victoria.

510 Troutbeck, R. J. (1990), Traffic Interactions at Roundabouts. 15th ARRB Conference, 511 26-31 August 1990, Darwin, Australia. Australian Road Research Board, 17-42.

$512 \mathrm{Wu}, \mathrm{N}$. (2001). "A universal procedure for capacity determination at unsignalized 513 (priority-controlled) intersections." Transportation Research Part B: Methodological, 514 35(6), 593-623.

515 Yap, Y. H., Gibson, H. M., and Waterson, B. J. (2013). "An International Review of 516 Roundabout Capacity Modelling." Transport Reviews, 33(5), 593-616. 


\section{$\underline{\text { Tables }}$}

Table 1: Roundabout sites in sample

\begin{tabular}{|l|l|l|}
\hline $\begin{array}{l}\text { Roundabout } \\
\text { reference name }\end{array}$ & \multicolumn{1}{|c|}{ Coordinates } & Entry arm(s) direction \\
\hline bassett & $50^{\circ} 56^{\prime} 27^{\prime \prime} \mathrm{N}, 1^{\circ} 24^{\prime} 25^{\prime \prime} \mathrm{W}$ & S and SW \\
\hline baswinc & $51^{\circ} 15^{\prime} 18^{\prime \prime} \mathrm{N}, 1^{\circ} 6^{\prime} 13^{\prime \prime} \mathrm{W}$ & SW and SE \\
\hline binfield & $51^{\circ} 17^{\prime} 8^{\prime \prime} \mathrm{N}, \quad 1^{\circ} 3^{\prime} 41^{\prime \prime} \mathrm{W}$ & $\mathrm{NE}$ and SW \\
\hline coralreef & $51^{\circ} 23^{\prime} 27^{\prime \prime} \mathrm{N}, 0^{\circ} 44^{\prime} 4^{\prime \prime} \mathrm{W}$ & $\mathrm{NW}$ \\
\hline hilllane & $50^{\circ} 56^{\prime} 3^{\prime \prime} \mathrm{N}, 1^{\circ} 25^{\prime} 9^{\prime \prime} \mathrm{W}$ & $\mathrm{W}$ \\
\hline imperial & $51^{\circ} 25^{\prime} 6^{\prime \prime} \mathrm{N}, \quad 0^{\circ} 58^{\prime} 33^{\prime \prime} \mathrm{W}$ & $\mathrm{SE}$ \\
\hline owrnmr & $51^{\circ} 23^{\prime} 5^{\prime \prime} \mathrm{N}, 0^{\circ} 47^{\prime} 35^{\prime \prime} \mathrm{W}$ & $\mathrm{S}$ and W \\
\hline peacock & $51^{\circ} 24^{\prime} 34^{\prime \prime} \mathrm{N}, 0^{\circ} 47^{\prime} 15^{\prime \prime} \mathrm{W}$ & $\mathrm{NE}$ and SE \\
\hline thornycroft & $51^{\circ} 15^{\prime} 56^{\prime \prime} \mathrm{N}, 1^{\circ} 6^{\prime} 29^{\prime \prime} \mathrm{W}$ & $\mathrm{S}, \mathrm{N}, \mathrm{W}, \mathrm{E}$ \\
\hline welshln & $51^{\circ} 21^{\prime} 32^{\prime \prime} \mathrm{N}, 0^{\circ} 58^{\prime} 15^{\prime \prime} \mathrm{W}$ & $\mathrm{S}$ and E \\
\hline
\end{tabular}


Table 2: Explanatory variables investigated in this study

\begin{tabular}{|l|c|c|c|c|}
\hline Variable & Units & Minimum & Mean & Maximum \\
\hline At-capacity entry flow, $\mathrm{Q}_{\mathrm{e}}$ & $\mathrm{pcu} / \mathrm{h}$ & 0 & 667 & 1920 \\
\hline Circulating flow, $\mathrm{Q}_{\mathrm{c}}$ & $\mathrm{pcu} / \mathrm{h}$ & 0 & 1266 & 2880 \\
\hline Exiting flow, $\mathrm{Q}_{\mathrm{x}}$ & $\mathrm{pcu} / \mathrm{h}$ & 0 & 958 & 2460 \\
\hline Inscribed circle diameter, $\mathrm{D}$ & $\mathrm{m}$ & 31 & 68 & 100 \\
\hline Lane width $10 \mathrm{~m}$ upstream, $\mathrm{W}_{\mathrm{L}}$ & $\mathrm{m}$ & 2.0 & 3.2 & 4.2 \\
\hline Entry curvature, $1 / \mathrm{r}$ & $\mathrm{m}^{-1}$ & $0(1 / \infty)$ & $1 / 74$ & $1 / 20$ \\
\hline Entry angle, $\phi$ & ${ }^{\circ}$ & 6.6 & 26.3 & 54.2 \\
\hline Circulation width, $\mathrm{W}_{\mathrm{C}}$ & $\mathrm{m}$ & 6.7 & 8.4 & 11.6 \\
\hline Entry-exit separation, $\mathrm{d}_{\text {sep }}$ & $\mathrm{m}$ & 13.8 & 39.7 & 95.7 \\
\hline Distance to previous entry, $\mathrm{d}_{\text {upe }}$ & $\mathrm{m}$ & 20.7 & 55.5 & 117.5 \\
\hline
\end{tabular}


Table 3: Parameter estimates and their standard errors from regression models; all parameters are significant at the $5 \%$ level except for that marked *

\begin{tabular}{|l|c|c|c|c|}
\cline { 2 - 5 } \multicolumn{1}{c|}{} & \multicolumn{2}{c|}{ Linear model 1 } & \multicolumn{2}{c|}{ Exponential model 2 } \\
\hline Parameter & Estimate & Std. Error & Estimate & Std. Error \\
\hline Intercept parameter & 1113.2 & 51.1 & -771.0 & 64.7 \\
\hline $\mathrm{Q}_{\mathrm{c}}$ & -0.952 & 0.038 & -0.00103 & 0.000045 \\
\hline $\mathrm{D}$ & 15.91 & 1.01 & 8.011 & 0.449 \\
\hline $\mathrm{d}_{\mathrm{sep}}$ & -5.988 & 1.458 & 6.997 & 0.963 \\
\hline $\mathrm{Q}_{\mathrm{x}}$ & $0.010^{*}$ & 0.024 & 0.057 & 0.007 \\
\hline $1 / \mathrm{r}$ & -7801.1 & 790.9 & 2088.0 & 325.2 \\
\hline $\mathrm{D} \times \mathrm{d}_{\mathrm{sep}}$ & -0.243 & 0.013 & -0.103 & 0.011 \\
\hline $\mathrm{Q}_{\mathrm{c}} \times \mathrm{D}$ & -0.003 & 0.001 & - & - \\
\hline $\mathrm{Q}_{\mathrm{c}} \times \mathrm{d}_{\text {sep }}$ & 0.015 & 0.001 & - & - \\
\hline $\mathrm{Q}_{\mathrm{c}} \times \mathrm{Q}_{\mathrm{x}}$ & 0.000108 & $1.63 \mathrm{E}-05$ & - & - \\
\hline $\mathrm{d}_{\mathrm{sep}} \times \mathrm{Q}_{\mathrm{x}}$ & 0.004 & 0.001 & - & - \\
\hline $\mathrm{Q}_{\mathrm{c}} \times 1 / \mathrm{r}$ & 7.51 & 0.67 & - & - \\
\hline $\mathrm{W}_{\mathrm{c}}$ & - & - & 40.67 & 5.54 \\
\hline Multiplicative parameter & - & - & 1580.1 & 26.1 \\
\hline
\end{tabular}


Table 4: Comparison of neural networks with best-performing variable sets

\begin{tabular}{|c|c|c|c|c|c|c|c|c|c|c|c|c|}
\hline \multirow[b]{2}{*}{$\begin{array}{c}\text { No. of } \\
\text { variables }\end{array}$} & \multicolumn{10}{|c|}{ Variables } & \multirow[b]{2}{*}{$\begin{array}{c}\text { Mean } \\
\mathrm{R}^{2}\end{array}$} & \multirow[b]{2}{*}{$\begin{array}{l}\text { Mean } \\
\text { RMSE }\end{array}$} \\
\hline & $Q_{c}$ & D & $W_{C}$ & $d_{\text {upe }}$ & $1 / r$ & $\mathrm{~W}_{\mathrm{L}}$ & $d_{s e p}$ & $\phi$ & $Q_{x}$ & $\begin{array}{l}\text { Wet/ } \\
\text { dry }\end{array}$ & & \\
\hline 1 & $\sqrt{ }$ & & & & & & & & & & 0.736 & 152.0 \\
\hline 2 & $\checkmark$ & $\checkmark$ & & & & & & & & & & \\
\hline 3 & $\checkmark$ & $\checkmark$ & & & & & $\checkmark$ & & & & 0.848 & 115.3 \\
\hline 4(a) & $\checkmark$ & $\checkmark$ & $\checkmark$ & & & & & & $\checkmark$ & & 0.865 & 111.3 \\
\hline $5(\mathrm{a})$ & $\checkmark$ & $\checkmark$ & $\checkmark$ & $\checkmark$ & & & & & $\checkmark$ & & 0.867 & 110.2 \\
\hline & $\checkmark$ & $\checkmark$ & $\checkmark$ & & & & $\checkmark$ & & & & 0.857 & 112.1 \\
\hline $5(b)$ & $\checkmark$ & $\checkmark$ & $\checkmark$ & & & & $\checkmark$ & & $\checkmark$ & & 0.862 & 112.1 \\
\hline All & $\sqrt{ }$ & $\checkmark$ & $\checkmark$ & $\sqrt{ }$ & $\sqrt{ }$ & $\checkmark$ & $\checkmark$ & $\checkmark$ & $\checkmark$ & $\checkmark$ & 0.877 & 106.2 \\
\hline
\end{tabular}


Table 5: Ranking of the explanatory variables (including interactions) by contribution to model fit, where \# denotes insignificant or weak contributions to model $R^{2}$ of less than $1 \%$

\begin{tabular}{|l|c|c|c|c|c|c|c|}
\cline { 2 - 9 } \multicolumn{1}{c|}{} & \multicolumn{9}{c|}{ Variables } \\
\cline { 2 - 9 } \multicolumn{1}{c|}{} & $\mathrm{Q}_{\mathrm{c}}$ & $\mathrm{D}$ & $\mathrm{d}_{\text {sep }}$ & $\mathrm{Q}_{\mathrm{x}}$ & $1 / \mathrm{r}$ & $\mathrm{W}_{\mathrm{C}}$ & $\begin{array}{c}\phi, \mathrm{d}_{\text {upe }}, \mathrm{W}_{\mathrm{L}}, \text { wet/dry, } \\
\text { queue duration }\end{array}$ \\
\hline Linear Model 1 & 1 & 2 & 3 & 4 & 5 & $\#$ & $\#$ \\
\hline Exponential Model 2 & 1 & 2 & 4 & 3 & 5 & 6 & $\#$ \\
\hline Neural Networks & 1 & 2 & 4 & 5 & 6 & 3 & $\#$ \\
\hline
\end{tabular}




\section{Figure Captions}

Figure 1: Measured variables for each entry lane.

Figure 2: At-capacity lane entry flows from surveyed entries, with local regression (loess) lines.

Figure 3: Class mean lane entry capacity flows from the middle lane of the east entry of Thornycroft roundabout, based on 30-second measurement time intervals.

Figure 4: Observed and predicted lane capacities ( $p c u / h)$ from international models. Figure 5: Comparison of actual against predicted capacities for the new empirical models, with loess fit lines.

Figure 6: Predicted lane entry capacities of models, by site.

Figure 7: Comparison of RMSE values between empirical models and international models.

Figure 8: Impact on entry capacity by separation distance $\left(d_{s e p}\right)$, exiting flow $\left(Q_{x}\right)$, diameter $(D)$ and circulating flow $\left(Q_{c}\right)$ in the regression models assuming other variables unchanged.

Figure 9: Comparison of capacities predicted by recalibrated models against the actual data from two sites reserved for validation. 